\title{
Effects of Heat Exchanger Characteristics on Optimized Intercooled Turbofan Engine Cycles
}

\author{
Takayuki Ito $^{1}$, Susumu Teramoto ${ }^{2}$ and Koji Okamoto ${ }^{3}$ \\ ${ }^{1}$ Graduate student, The University of Tokyo; currently at Polyphony Digital Inc. \\ ${ }^{2}$ Department of Aeronautics and Astronautics, The University of Tokyo \\ ${ }^{3}$ Department of Advanced Energy, The University of Tokyo \\ 5-1-5 Kashiwano-ha Kashiwa-shi, Chiba 227-8561, JAPAN
}

\begin{abstract}
The thermodynamic cycle of an intercooled turbofan engine was optimized by considering various characteristics of intercoolers (ICs). Sixty-three intercooled turbofan engines were optimized using an evolutionary algorithm. Thirty-nine design parameters were analyzed using proper orthogonal decomposition, and the effects of the IC performance on the engine thermodynamic cycle were examined. The improvement in net fuel consumption due to intercooling strongly depends on the characteristics of the IC fin, and the net fuel consumption is minimized at a particular fin height. By using ICs with an appropriate fin height, intercooling increases the overall pressure ratio, while increasing the heat transfer surface areas and cross-sectional areas of the ICs realizes high effectiveness and low pressure losses. The pressure ratio partition between the intermediate- and high-pressure compressors is determined according to incompatible characteristics of the IC, such as pressure losses and the temperature difference between the inlet and outlet of the IC. Because the weight of the IC is proportional to its fin area density, increasing the fin area density reduces the net fuel consumption. However, it does not significantly influence the thermodynamic cycle of the engine.
\end{abstract}

\section{Introduction}

Most commercial aircraft engines are turbofan engines that run on a Brayton cycle. The engine fan is driven by a directly connected lowpressure turbine (LPT), which generates most of the thrust. Each component of a turbofan engine attains approximately $90 \%$ efficiency. However, the engine performance is limited by the turbine inlet temperature, compressor outlet temperature, compressor outlet blade height, and circumferential velocity ratio between the fan and LPT. Therefore, there is not much scope to improve the efficiency of the turbofan engine. As such, studies have been performed over the past decade to improve the engine performance using heat exchangers, especially in Europe [1-11].

The improvement in fuel consumption by intercooling depends on the characteristics of the heat exchanger, such as its effectiveness, pressure loss, weight, and size. Some studies have reported that intercooling improves the fuel consumption by $4 \%$ [3] or 3\% [4]; however, other studies have contradicted these findings [6].

Shinmyo et al. [12] optimized a three-spooled turbofan engine equipped with intercoolers (ICs) between the intermediate-pressure compressor (IPC) and high-pressure compressor (HPC), as shown in Fig. 1, by considering the effects of the engine weight. They determined that the thrust-specific fuel consumption (TSFC) of a largesized engine is reduced $2.6 \%$ by intercooling; however, the weight penalty suppresses the reduction in the total fuel consumption to about $1 \%$.

Simple analysis from a thermodynamics textbook has shown that an IC with a large decrease in the hot-gas temperature and low pres-

Manuscript Received on May 2, 2014

Review Completed on November 17, 2014 sure loss would increase both the thermodynamic efficiency and the specific thrust of a core engine, which would reduce the fuel consumption of a turbojet engine. However, the design for the thermodynamic cycle of an intercooled turbojet engine becomes much more complex when the weight and volume of the IC are considered. That is, an IC with a large hot-gas temperature decrease and low pressure loss is large and heavy in general; therefore, such an IC does not necessarily improve the net performance of an aero-propulsion system. In addition, many design parameters influence the pressure loss and hot-gas temperature decrease of an IC, so examining the influence of a design parameter on the net performance of an aero-propulsion system is not straightforward. For example, the following three thermodynamic cycles have a large IC hot-gas temperature decrease: an IC with many bypass flows introduced into the IC cold-gas path, a thermodynamic cycle with a large IPC pressure ratio and thus a large temperature difference at the IC inlet, and an IC with a large heat transfer area. However, it is not self-evident which one is the best for an aero-propulsion system.

The quantitative evaluation of intercooled turbofan engines can be difficult because the optimum thermodynamic cycle of the engine differs when a heat exchanger characteristic is changed. As such, the performance of an engine optimized for a particular heat exchanger cannot be evaluated when its heat exchanger is replaced. Therefore, it is necessary to compare intercooled turbofan engines optimized with ICs to maximize the engine performance. However, in this case, evaluating how each design parameter of the heat exchanger affects the engine performance is difficult owing to the characteristics of the heat exchanger and design parameters of the engine itself, e.g., when the pressure ratio and turbine inlet temperature are changed simultaneously.

This study focused on two design parameters that represent the IC performance: the fin heat resistance, which is a function of the heat transfer coefficient and heat transfer area, and the fin weight. Parametrically optimized turbojet engine cycles with different fin heat resistances and fin weights were compared to determine the optimum turbojet engine cycle for a given heat resistance and fin weight and how the IC performance affects the optimum cycle parameters of the engine system.

\section{Numerical Method}

\section{Target Engine}

For the analysis target, the same intercooled turbofan engine model as that of Shinmyo et al. [12] was used,i.e., an engine model in which the compressed, high-temperature air leaving the IPC is cooled inside ICs and then directed to the HPC, as shown in Fig. 1. The heat exchangers consist of compiled corrugated fins so that high- and lowtemperature air travels between these fins, as shown in Fig. 2(a). The heat exchanger modules are arranged around the HPC, as shown in Fig. 2(b).

The performance of this heat exchanger is affected by its fin 
height (interval of each compiled plate $h$ ) and fin area density (product of the fin's thickness and material density $\rho \times t$ ), which directly affect the weight of the heat exchanger. As such, the heat transfer coefficient increases as the fin height decreases. Furthermore, the effectiveness of the heat exchanger is improved because the heat transfer area per volume increases. However, because friction also increases, the pressure losses increase.
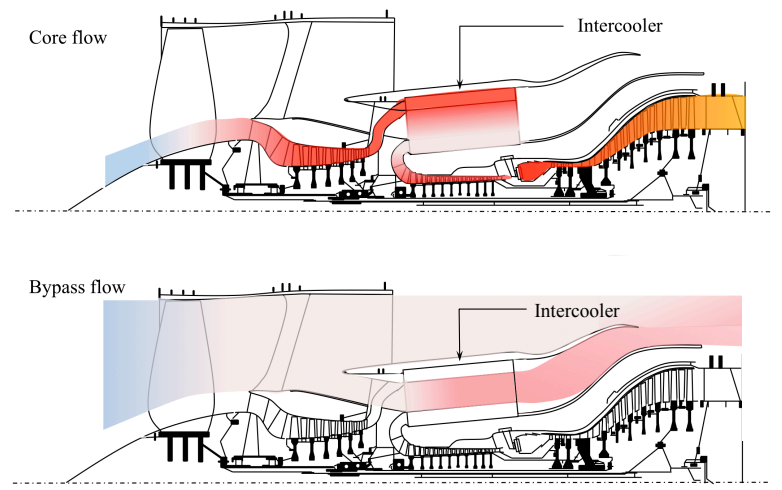

Fig. 1. Intercooled engine

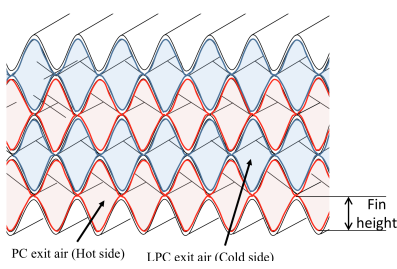

(a) Primary surface heat exchanger

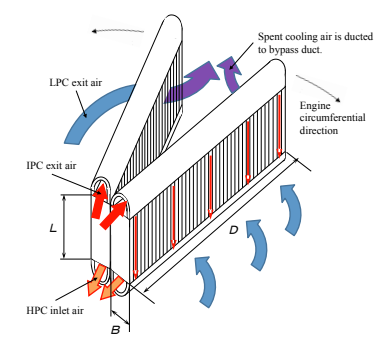

(b) Heat exchanger module
Fig. 2. Heat exchanger model

\section{Analysis Models and Cycle Optimization}

The engine was evaluated using the same analysis module as Shinmyo et al. [12]. This consisted of three modules: (1) a cycle analysis module to estimate the engine thermodynamic cycle derived from engine design parameters such as the pressure ratio, bypass ratio, and turbine inlet temperature as well as the efficiencies of each engine component; (2) a heat exchanger module to estimate the features of heat exchangers using the E-NTU method [13], which is based on the experimental values of the heat transfer coefficients and friction coefficients suggested by Staseik [14]; and (3) a weight evaluation module to estimate the weight penalty based on NASA-TMX-2406 [15], which considers the average circumferential velocities and aerodynamic load coefficients of the compressors and turbines.

The analysis object was set as a large two-aisle aircraft (maximum gross weight at takeoff $=297,800 \mathrm{~kg}$ ) equipped with two 95,000 lbf-class engines (maximum thrust $=424,800 \mathrm{~N}$ ) because Shinmyo et al. [12] reported that installing ICs in such an aircraft had a significant effect. The optimizations were performed using an evolutionary algorithm $[16,17]$, and the objective function was set to the fuel consumption under cruising conditions (Mach 0.85 at 11,000 $\mathrm{m})$.

The cruise thrust $F_{\text {cruise }}$ was evaluated according to the maximum takeoff weight of the aircraft $W_{\mathrm{MTO}}$, the number of engines $N_{E}$, the cruise lift-to-drag ratio $L / D$, the baseline engine weight $W_{E b a s e}$, and the designed engine weight $W_{E}$ using the following equation:

$$
F_{\text {cruise }}=\frac{W_{\text {MTO }}}{N_{E} \cdot L / D} \frac{W_{\mathrm{MTO}}+N_{E}\left(W_{E}-W_{E \text { base }}\right)}{W_{\mathrm{MTO}}} .
$$

\section{Design Parameters and Constraints}

Tables 1 and 2 list the design parameters and constraints, respectively. The maximum fin area density was set to $0.6 \mathrm{~kg} / \mathrm{m}^{2}$. This corresponded to a $0.08 \mathrm{~mm}$ thick sheet of stainless steel, which was the lightest weight for the current circumstances.

When a 95,000 lbf-class turbofan engine is optimized with ICs under the constraints listed in Table 2, its thermodynamic cycle is strongly influenced by the compressor outlet temperature [12]. However, when heat exchangers are not equipped with the ICs, the overall pressure ratio is reduced to 50 because of the outlet-to-inlet temperature ratio of the compressor. Conversely, when heat exchangers are equipped with the ICs, the TSFC improves because the specific thrust generated by the core is enhanced by the ICs, which increases the bypass ratio.

In this study, the fin height and area density of the heat exchangers were set as constraints. The 10 design parameters in Table 1 were optimized using an evolutionary algorithm for nine different fin heights and seven different fin area densities $(9 \times 7=63$ cases in total). Then, the following 37 parameters of the optimized solutions were analyzed.

Engine performance parameters

Fuel consumption fuel consumption rate under cruising condi-

$\begin{array}{ll}\text { TSFC } & \text { tions }[\mathrm{kg} / \mathrm{s}] \\ \text { thrust specific fuel consumption }[\mathrm{kg} / \mathrm{s} / \mathrm{N}]\end{array}$

Turbofan engine design parameters

BPR bypass ratio

IPR pressure ratio of intermediate pressure compressor

HPR pressure ratio of high pressure compressor

OPR overall pressure ratio
IC design parameters ICBPR

Fin surface area

Fin surface area density

NTU

IC performance parameters

IC hot inlet temperature IC hot side inlet temperature, i.e., temperature of IPC exit [K]

IC hot outlet temperature $\quad$ IC hot side exit temperature, i.e., temperature of HPC inlet [K]

Temperature difference $\quad$ IC hot side temperature drop

IC effectiveness temperature effectiveness of IC [K]

IC pressure loss parameters

Reynolds number (hot)

Reynolds number (cold)

Velocity (hot)

Velocity (cold)

Pressure loss (hot)

Pressure loss (cold)

Pressure loss (bypass)

Reynolds number of hot flow path Reynolds number of cold flow path bulk velocity at hot flow path $[\mathrm{m} / \mathrm{s}]$ bulk velocity at cold flow path $[\mathrm{m} / \mathrm{s}]$ pressure loss at IC hot flow path $[\mathrm{Pa}]$ pressure loss at IC cold flow path [Pa] pressure loss at bypass flow, $[\mathrm{Pa}]$

Weight and dimension parameters Weights

IPC, HPC, combustor, HPT, IPT, LPT, IC, structure, core engine without IC, core engine including IC $[\mathrm{kg}]$

Diameters

\section{Data Analysis}

The obtained solutions were 63 data points distributed in a 39dimensional space and included the fin height and area density. The objective of this study was to determine the correlations among 
Table 1. Design parameters

\begin{tabular}{lcc}
\hline \hline Parameter & Min. & Max. \\
\hline Fan pressure ratio & 1.4 & 1.8 \\
IPC pressure ratio & 3.0 & 12.0 \\
HPC pressure ratio & 3.0 & 25.0 \\
Bypass ratio & 3.0 & 10.0 \\
TIT [K] & 1500 & 1900 \\
\hline IC bypass ratio & 0.05 & 0.7 \\
IC width (B, Fig. 2(b)) [m] & 0.01 & 1.2 \\
IC height (L, Fig. 2(b)) [m] & 0.01 & 1.2 \\
IC length (D, Fig. 2(b)) [m] & 0.1 & 2.5 \\
Number of IC modules & 1 & 50 \\
\hline Fin height [mm] & 2 & 12 \\
Fin area density $(\rho \times t)\left[\mathrm{kg} / \mathrm{m}^{2}\right]$ & 0.2 & 0.6 \\
\hline \hline
\end{tabular}

Table 2. Constraints

\begin{tabular}{c|c}
\hline \hline Parameter & Limit \\
\hline Minimum blade height at HPC exit & $15 \mathrm{~mm}$ \\
Maximum temperature at HPC exit & $950 \mathrm{~K}$ \\
Maximum fan diameter & $2.794 \mathrm{~m}$ \\
\hline Maximum IC module height & $\frac{1}{4}($ fan tip dia. - IPC tip dia.) \\
Maximum IC module axial length & HPC length + combustor length \\
IC module circumference width & HPC circumference length \\
\hline \hline
\end{tabular}

these parameters and examine how the characteristics of the heat exchanger affect the performance of intercooled turbofan engines.

If two parameters are selected from the 39 design parameters and plotted on a 2D graph, as shown in Fig. 3, their correlation can be understood. However, such self-evident correlations between the OPR and TSFC or between the IPR and IC hot inlet temperature, as shown in Fig. 3, are of little interest. In addition, some relations such as that between the IPC diameter and TSFC are not easily understood, even though they have a strong physical correlation. Therefore, it is not possible to understand the entire design space by only looking at the correlations between two parameters.

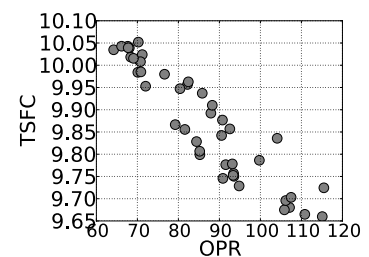

(a) OPR - TSFC

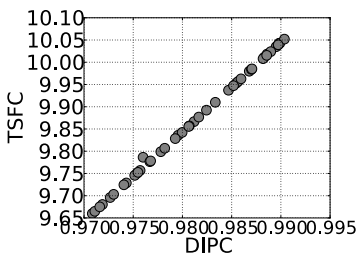

(b) IPC diameter - TSFC
Fig. 3. 2D plot example of design parameters

For these reasons, proper orthogonal decomposition (POD) $[18,19]$, which is an analysis method for multi-dimensional data, was used to analyze the data in this study. POD is used in various fields such as data compression, image processing, optimization [20], and fluid dynamics [19]. It represents the distributed data in a multidimensional space by using an orthogonal coordinate system, which differs from the original one. To determine the state of the data in a multi-dimensional space, POD obtains new coordinate axis directions to obtain higher correlations with the data. Then, the deviations of the data around the new coordinate axes are derived followed by the POD bases, energy ratios, and modal coordinates. The POD basis serves as the new coordinate system so that each coordinate axis obtains the strongest correlation with the data. The energy ratio is the deviation of the data projected on the POD basis, and the modal coordinates are the coordinates of the data points in the POD basis A POD basis that includes a large energy ratio is a coordinate axis that properly expresses the deviation of the data. Therefore, the directions of the POD basis can be used to determine how the data consists of compiled basic modes.

\section{Results}

\section{Fuel Consumption}

The optimized design parameters of three representative cases are listed in Table 3: a conventional turbofan without an IC, an intercooled turbofan with an optimized fin hight $\left(\rho t=0.4 \mathrm{~kg} / \mathrm{m}^{2}\right.$, $h=3 \mathrm{~mm})$ and an intercooled turbofan with a tall fin $\left(\rho t=0.4 \mathrm{~kg} / \mathrm{m}^{2}\right.$, $h=10 \mathrm{~mm})$.

Fig. 4 shows the improvement ratios in the fuel consumption, which are defined as $\Delta F C=\frac{F C_{0}-F C_{I C}}{F C_{0}} \times 100$, where $F C_{I C}$ and $F C_{0}$ are the optimized fuel consumptions with and without ICs, respectively. The fuel consumption was improved even with a fin area density of $0.6 \mathrm{~kg} / \mathrm{m}^{2}$, i.e., the densest fin area, but the improvement was small. Thus, it was necessary to use very lightweight heat exchangers with a fin area density of $0.2 \mathrm{~kg} / \mathrm{m}^{2}$ to achieve an improvement greater than $2 \%$. In addition, decreasing the fin height improved the fuel consumption. However, for fin heights less than $3 \mathrm{~mm}$, the fuel consumption deteriorated. The minimum fuel consumption was achieved when the fin height was 3 or $4 \mathrm{~mm}$.

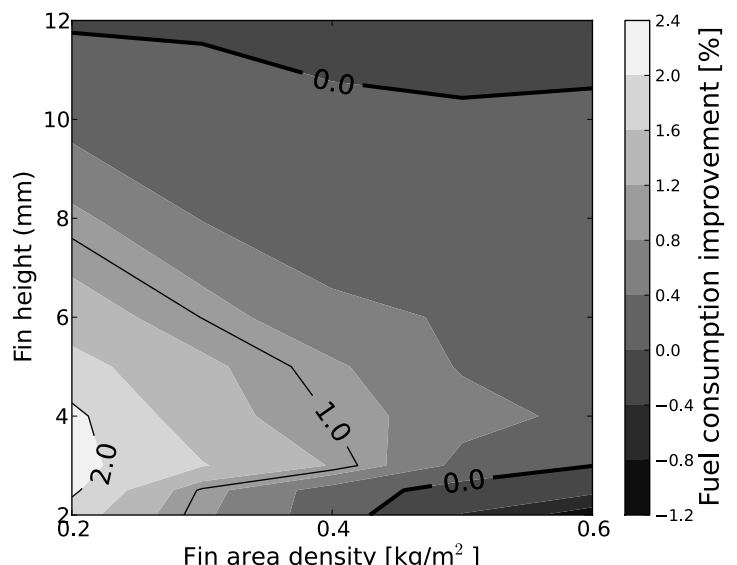

Fig. 4. Improvement in fuel consumption

The characteristics of the IC affect $\triangle F C$ by improving the thermodynamic cycle efficiency $\left(\Delta \eta_{\text {core }}\right)$, weight penalty $\left(\Delta \eta_{W}\right)$, and thrust loss due to pressure loss $\left(\Delta \eta_{P}\right)$. When the weight penalty $\Delta \eta_{W}$ is approximated by $\Delta \eta_{W}=-\frac{N_{e} W_{I C}}{W_{M T O}}$ and the thrust loss due to pressure loss in the IC $\Delta \eta_{P}$ is approximated by $\Delta \eta_{P}=-\frac{P_{13}-P_{16}}{P_{13}-P_{a m b}}$, the thermodynamic cycle efficiency $\Delta \eta_{\text {core }}$ is expressed as

$$
\Delta \eta_{\text {core }}=\Delta F C-\Delta \eta_{P}-\Delta \eta_{W},
$$

where $N_{e}, W_{I C}, W_{M T O}, P_{13}, P_{16}, a n d P_{a m b}$ are the number of engines, weight of the IC module, maximum takeoff weight, pressure at the exit of the fan, pressure at the nozzle inlet of the bypass duct, and atmospheric pressure, respectively.

When $\Delta \eta_{\text {core }}, \Delta \eta_{P}$, and $\Delta \eta_{W}$ in Fig. 5 were compared around $h=4 \mathrm{~mm}$, i.e., where the fuel consumption showed improvement, $\Delta \eta_{\text {core }} \sim 5-6 \%, \Delta \eta_{P} \sim-3 \%$ to $-3.5 \%$, and $\Delta \eta_{W} \sim-1 \%$ to $-1.5 \%$. Therefore, the pressure loss was dominant compared to the weight penalty. 
Table 3. Optimized engine cycles at the sea-level static design point

\begin{tabular}{|c|c|c|c|c|}
\hline \multirow{2}{*}{\multicolumn{2}{|c|}{ Parameter }} & \multirow[t]{2}{*}{ conventional } & \multicolumn{2}{|c|}{ intercooled } \\
\hline & & & $\rho t=0.4 \mathrm{~kg} / \mathrm{m}^{2}, h=3 \mathrm{~mm}$ & $\rho t=0.4 \mathrm{~kg} / \mathrm{m}^{2}, h=10 \mathrm{~mm}$ \\
\hline \multicolumn{5}{|c|}{ Design parameter } \\
\hline Fan pressure ratio & & 1.80 & 1.80 & 1.80 \\
\hline IPC pressure ratio & & 8.32 & 5.77 & 6.97 \\
\hline HPC pressure ratio & & 3.21 & 11.07 & 6.02 \\
\hline Overall pressure ratio & & 48.17 & 107.48 & 71.19 \\
\hline Bypass ratio & & 5.65 & 5.87 & 5.65 \\
\hline Turbine inlet temp. & $\mathrm{K}$ & 1899.8 & 1900.0 & 1900.0 \\
\hline IC bypass ratio & & & 0.172 & 0.104 \\
\hline IC width & $\mathrm{m}$ & & 0.409 & 0.618 \\
\hline IC height & $\mathrm{m}$ & & 0.803 & 0.793 \\
\hline IC length & $\mathrm{m}$ & & 1.497 & 1.008 \\
\hline IC module number & & & 7 & 3 \\
\hline \multicolumn{5}{|c|}{ Constraints } \\
\hline HP exit temperature & $\mathrm{K}$ & 949.9 & 950.0 & 950.0 \\
\hline HPC blade height & $\mathrm{mm}$ & 47.7 & 18.6 & 30.1 \\
\hline Fan diameter & $\mathrm{m}$ & 2.794 & 2.794 & 2.794 \\
\hline \multicolumn{5}{|c|}{ Performance } \\
\hline Fan inlet mass flow & $\mathrm{kg} / \mathrm{s}$ & 1204.7 & 1204.8 & 1204.8 \\
\hline takeoff Thrust & $\mathrm{kN}$ & 424.8 & 424.8 & 424.8 \\
\hline (cruise Thrust) & $\mathrm{kN}$ & $(83.7)$ & $(85.0)$ & $(84.0)$ \\
\hline SFC & $\mathrm{mg} / \mathrm{s} / \mathrm{N}$ & 10.019 & 9.703 & 10.024 \\
\hline IC efficiency & $\%$ & & 0.554 & 0.280 \\
\hline Bypass duct pressure loss & $\%$ & & 3.9 & 2.1 \\
\hline IC core pressure loss & $\%$ & & 7.3 & 6.2 \\
\hline cruise Fuel consumption & $\mathrm{kg} / \mathrm{h}$ & 5185.5 & 5124.4 & 5181.5 \\
\hline Weight (core w/o IC) & $\mathrm{kg}$ & 6498.5 & 6695.0 & 6636.6 \\
\hline Weight (IC) & $\mathrm{kg}$ & & 2058.4 & 269.5 \\
\hline Weight (total) & $\mathrm{kg}$ & 6498.5 & 8753.4 & 6906.2 \\
\hline
\end{tabular}
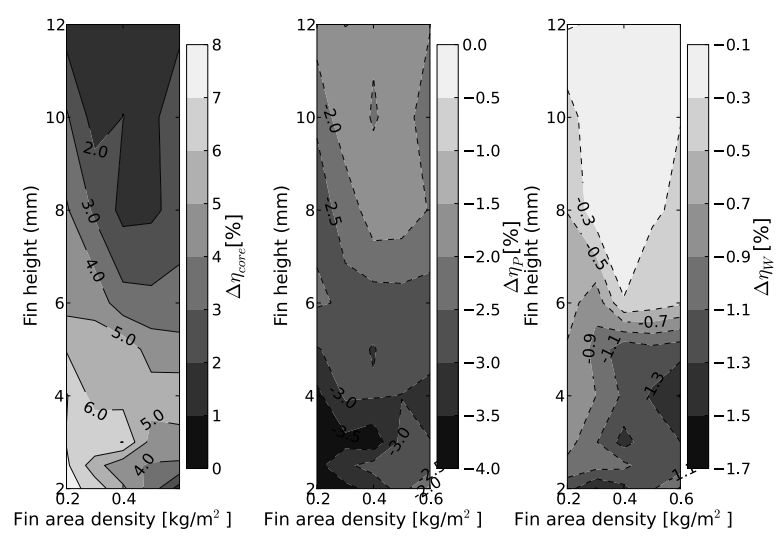

(a) $\Delta \eta_{\text {core }}$

(b) $\Delta \eta_{P}$

(c) $\Delta \eta_{W}$

Fig. 5. Contributions of pressure loss $\Delta \eta_{P}$, IC weight penalty $\Delta \eta_{W}$ and other effects $\Delta \eta_{\text {core }}$ to fuel consumption

\section{POD Modes}

To understand the behavior of the optimized solutions when the fin height (or compactness) and fin area density were changed, the correlations among the design parameters were visualized using POD. Table 4 lists the energy ratios of each mode. Note that $94 \%$ of the total entropy (or total energy ratio) of the original data was contained between the first and fourth modes. This means that the behaviors of the optimized solutions can mainly be expressed by compiling these four modes. Fig. 6 shows the POD modes for increasing energy ratios so that the correlations among the parameters can be determined.
THE FIRST MODE is the primary mode and contained $59.5 \%$ of the total entropy. When the parameters related to the thermodynamic cycle of the engine were observed, there was a positive correlation between the fin height and fuel consumption. In addition, according to the correlations among the fin height, HPR, IPR, and OPR, the HPR and OPR were larger for smaller fin heights, while the IPR is smaller. Consequently, the fuel consumption was improved.

In terms of the parameters related to the heat exchangers, the heat transfer area of the fin increased when the fin height was decreased, and the ICBPR, i.e., amount of fan bypass air directed to the ICs, increased. Thus, the effectiveness of the ICs can be assumed to have been enhanced because the heat transfer area and amount of fan bypass air were increased. As the result, the temperature drop in the ICs also increased. When the pressure losses in the ICs, i.e., pressure loss (hot) and pressure loss (cold), were investigated, the first mode was unchanged.

For the parameters related to the pressure losses in the ICs, the increased heat transfer area and decreased Reynolds number increased the pressure loss. The decreased flow velocities in the ICs (velocity (hot) and velocity (cold)) reduced the pressure loss. Therefore, the pressure losses barely changed in the first mode because those factors canceled each other out. For these reasons, the first mode realized low pressure losses and high effectiveness for the heat exchangers through the transfer of a large amount of cold bypass air into the large-sized ICs.

When the dimensions and weights of the engine were examined by following the changes in the IPR and HPR, the sizes and weights of the IPC and IPT were reduced, and those of the HPC and HPT increased. The engine weight without the ICs did not significantly change; however, the total engine weight with the ICs increased. In addition, the effect of the change in fin area density on the fuel consumption was negligible because the correlation with the fin area density was low in the first mode. Thus, the first mode indicated the following:

- A compact heat exchanger (small fin height and large fin surface area density) enables a large amount of heat exchange 
and makes the OPR larger. This improves the engine performance.

- Pressure losses in the ICs can be reduced by reducing the air flow velocities.

- The fin area density has little influence on the optimized cycle.

Therefore, the first mode is the primary mode for improving the engine performance using heat exchangers.

THE SECOND MODE had $24.0 \%$ of the total entropy. As shown in Fig. 6, the second mode was not correlated with the TSFC and fuel consumption. However, it had a positive correlation with the pressure losses in the ICs, IPR, and IC inlet temperature. In terms of the parameters determining the dimensions of the ICs, the second mode had a positive correlation with the fin height and negative correlation with the fin area density. In addition, there was a positive correlation between the IPR and IC inlet temperature (or IPC exit temperature) and a negative correlation between the fin height and fin area density. Therefore, the second mode indicated that the pressure losses tends to increase for smaller IC fin heights, and the IPR tends to increase.

THE THIRD AND FOURTH MODES had only 5\% of the total entropy, so it was difficult to clearly determine the relationships among the parameters. The third mode had relatively high correlations with the fin area density, fuel consumption, and engine weight. Therefore, the third mode can be assumed to correspond to the increase in fuel consumption owing to the weight penalty, i.e., the increased weight from the heat exchangers. The third mode showed few correlations with the other parameters. The fourth mode was related to the pressure losses in the heat exchangers.

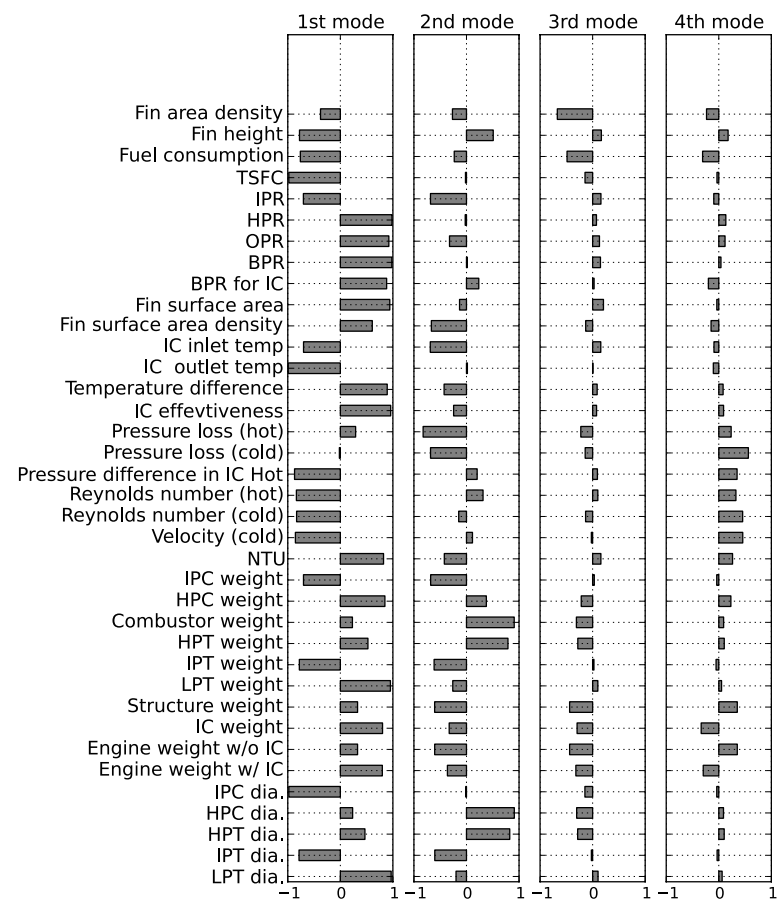

Fig. 6. POD modes

\section{Modal Coordinates}

Fig. 7 shows the modal coordinates of the first and second modes to demonstrate how the heat exchanger characteristics affect the engine performance.
Table 4. Energy ratio of principal modes

\begin{tabular}{lcc}
\hline \hline & Energy ratio & Cumulative energy ratio \\
\hline First mode & $59.5 \%$ & $59.5 \%$ \\
Second mode & $24.0 \%$ & $83.5 \%$ \\
Third mode & $5.4 \%$ & $88.9 \%$ \\
Fourth mode & $5.2 \%$ & $94.2 \%$ \\
\hline \hline
\end{tabular}

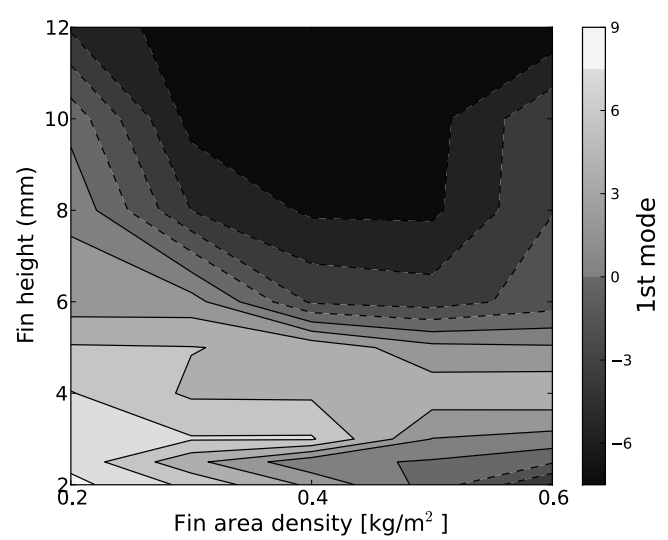

(a) First mode

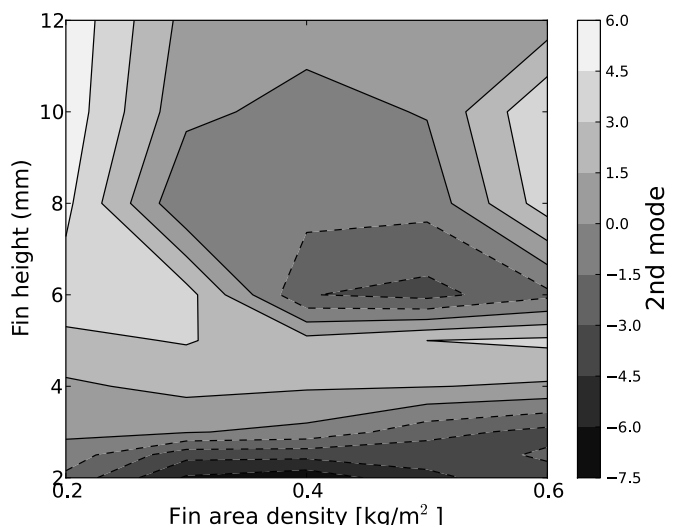

(b) Second mode

Fig. 7. POD modal coordinates

FIRST MODE The modal coordinates of the first mode primarily changed at fin heights of $h=2 \mathrm{~mm}$ and $h=6 \mathrm{~mm}$. Because the first mode is the primary mode for improving the engine performance using heat exchangers, intercooling was found to have a substantial effect between fin heights of $h=2 \mathrm{~mm}$ and $h=6 \mathrm{~mm}$. However, it did not appear to have any effect in other ranges.

Fig. 8 shows the ratios of the IC lengths and heights over these maximum values. Near a fin height of $4 \mathrm{~mm}$, i.e., where the maximum improvement in fuel consumption was realized, the ratios of the IC lengths and heights were more than $90 \%$. Thus, the ICs derived by the optimization increased to these maximum values. For cases that can improve the TSFC, large heat exchangers with low pressure losses and high temperature efficiencies were confirmed to be optimum for ICs. Fig. 9 shows that the ICBPR, i.e., amount of cooling air, significantly changed for a fin height of $h=6 \mathrm{~mm}$. For $h<6$ $\mathrm{mm}$, approximately $16 \%$ of the bypassed air was transferred into the ICs. However, for $h>6 \mathrm{~mm}$, this decreased to approximately $8 \%$, which is near the lower limit given in Table 1.

These results indicate that the fin height (heat transfer area per volume) dominates the optimized cycles. An intercooled turbofan 


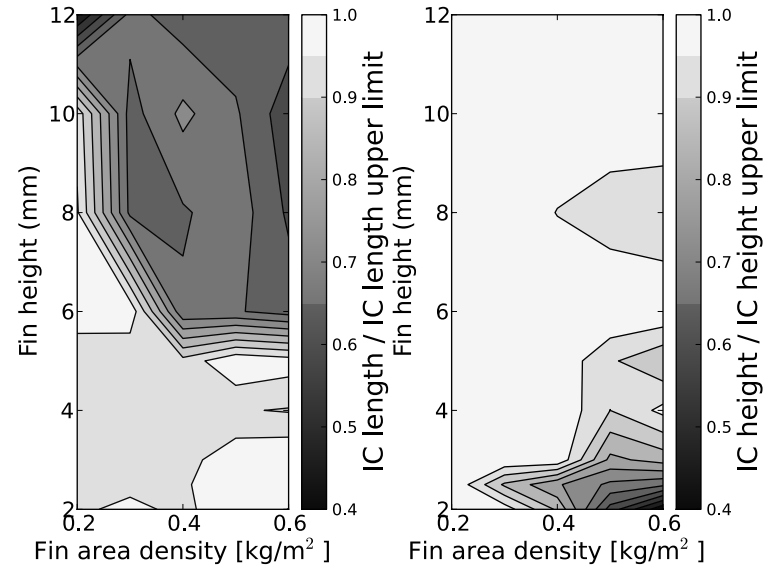

Fig. 8. IC size

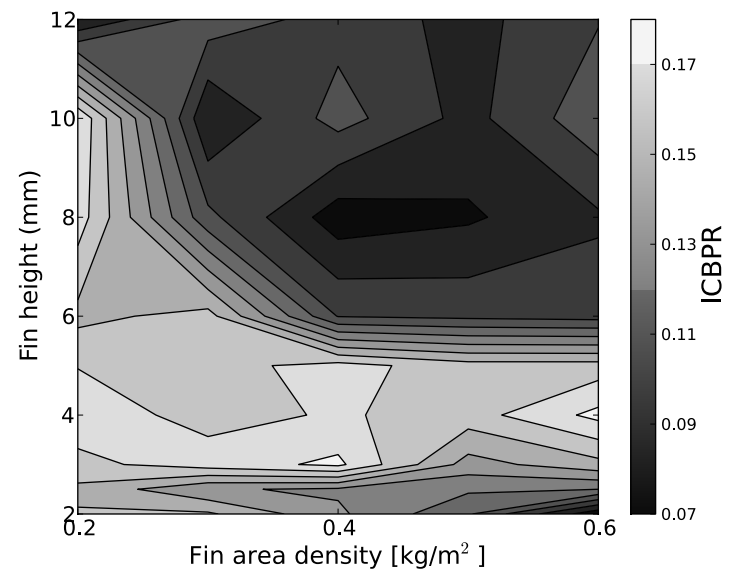

Fig. 9. IC bypass ratio

engine with a relatively small fin height is optimal for relatively large ICs, which can be nearly as large as these maximum available sizes. Because an IC, which has a large heat transfer area per volume, has a high level of effectiveness, it is optimized to reduce the flow velocities, which reduces pressure losss. On the other hand, an engine with a relatively large fin is optimal when it is equipped with relatively smaller ICs. Because an IC, which has a small heat transfer area per volume, does not have sufficient effectiveness, it is optimal to reduce the ICBPR, which will reduce the pressure losses and weight penalty. In addition, when the fin height is significantly small, the pressure losses in the ICs dominate. Thus, the engine is optimal for smaller heights and wet area while the cross-sectional area of the flow passages are kept hot.

The contour of the first mode, as shown in Fig. 7(a), was approximately horizontal for the fin heights $h<5 \mathrm{~mm}$. For $\rho t<0.3$ $\mathrm{kg} / \mathrm{m}^{2}$, i.e., very light fin area densities, the values of the "Length of IC/maximum length of IC" in Fig. 8 increased to between $90 \%$ and $95 \%$, although the fin area density had little influence on the thermodynamic cycle.

SECOND MODE The second mode had negative peaks in the areas near $h<3 \mathrm{~mm}$ and $h=6 \mathrm{~mm}$ and $\rho t>0.4 \mathrm{~kg} / \mathrm{m}^{2}$. Fig. 10 indicates that the second mode peaks corresponded to the areas of large pressure losses in the ICs, and the modal coordinates of the first mode were small.
Fig. 11 shows the friction factors and flow velocities, which are related to the pressure losses in the ICs. The friction coefficient [14] in the IC is derived by

$$
f=0.0717855 \sqrt{2028.955 / \operatorname{Re}},
$$

where Re is the Reynolds number whose reference length is the fin height. Therefore, the increased pressure losses in the ICs for $h<$ $3 \mathrm{~mm}$ were caused by the increasing friction coefficient owing to the low Reynolds number of the flows. The large negative modal coordinates for $h=6 \mathrm{~mm}$ and $\rho t>0.4 \mathrm{~kg} / \mathrm{m}^{2}$, which were caused by the increase in the flow velocities through the short lengths of the ICs, were derived to optimize the first mode.

Parameters of Heat Exchangers and Engine Cycles Based on the modal coordinates discussed above, the following relations among the first and second modes and the parameters of the heat exchangers were clarified. There is an optimal value for the fin height. When the fin height is too large, there is insufficient heat transfer in the ICs. Therefore, the volume of the ICs is reduced to optimize the first mode. Consequently, the flow velocities through the ICs increase, which causes the pressure losses to increase. On the other hand, when the fin height is too small, the pressure losses increase owing to the flow passages being too narrow. Thus, the volume of the ICs is reduced to optimize the first mode. In the area where the first mode is optimized to make the ICs smaller, the second mode can be distinguished, and the IPR is increased.

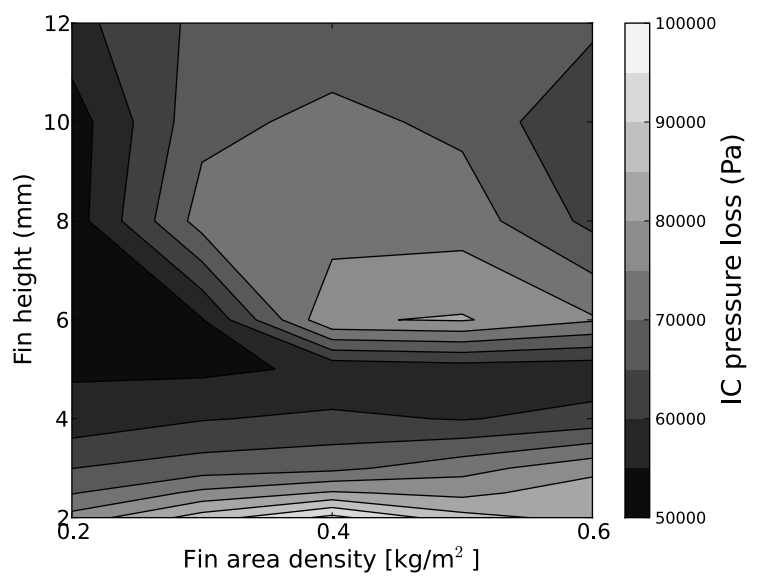

Fig. 10. IC pressure loss (hot)

\section{Conclusions}

Intercooled turbofan engines were optimized for various design parameters. POD was shown to be effective at analyzing these optimized solutions.

Based on the analysis of the intercooled turbofan engines, the following was determined:

- For an intercooled turbofan engine with the compact heat exchangers assumed in this study, the pressure losses are predominant over the weight penalty. Therefore, the optimization involves reducing pressure losses.

- When heat exchangers with a large heat transfer surface area per volume are used, the sizes of the IC modules are near the maximum available scale, and the ICBPR is increased. As a consequence, low pressure loss and high effectiveness of the ICs are realized such that an engine with a high HPR becomes the optimum thermodynamic cycle.

- When heat exchangers with a small heat transfer surface area per volume are used, the heat exchangers and ICBPR are reduced such that the pressure losses are reduced. 


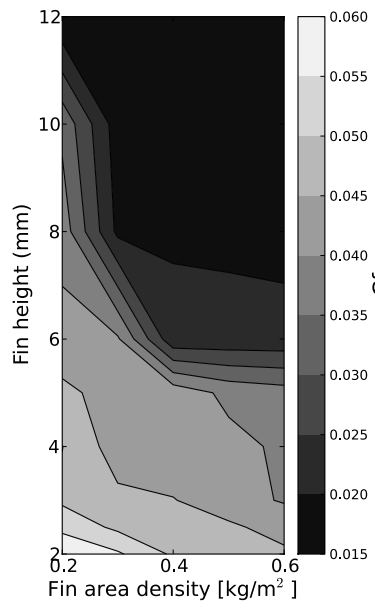

(a) friction coefficient

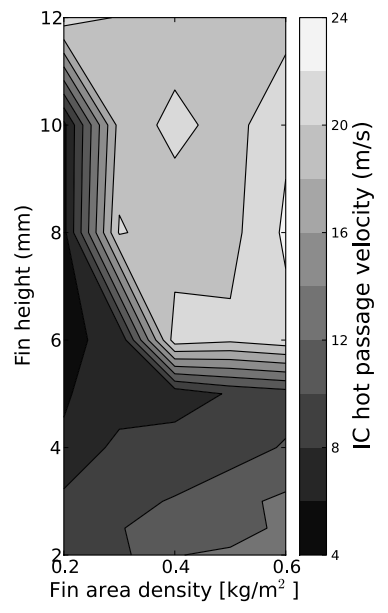

(b) flow velocity
Fig. 11. IC hot passage loss parameters

- When the fin area density is very low, the module of the heat exchangers increases in some cases; however, the influence of the fin area density on the optimized thermodynamic cycle is insignificant.

- When heat exchangers are accompanied by high pressure losses, the engine is optimal when the heat transfer is reduced and the IPR is increased.

\section{References}

[1] Konstantinos G. Kyprianidis, Tomas Grönstedt, S.O.T. Ogaji, P. Pilidis, and R. Singhi. Assessment of future aero engine designs with intercooled and intercooled recuperated cores. Number ASME GT2010-23, 2010 .

[2] Colin F. McDonald, Aristide F. Massardo, Colin Rodgers, and Aubrey Stone. Recuperated gas turbine aeroengines, part I: early development activities. Aircraft Engineering and Aerospace Technology, 80(2):139157, 2008.

[3] Lei Xu, Bernhard Gustafsson, and Tomas Grönstedt. Mission optimization of an intercooled turbofan engine. In International Symposium on Air Breathing Engines, number ISABE-2007-1157, 2007.

[4] Lei Xu and Tomas Grönstedt. Design and analysis of an intercooled turbofan engine. Journal of Engineering for Gas Turbines and Power, 132(11), 2010.

[5] Andrew M. Rolt and Nick J. Baker. Intercooled turbofan engine design and technology research in the EU framework 6 NEWAC programme. In International Symposium on Air Breathing Engines, number ISABE2009-1278, 2009.

[6] Tilemachos Papadopoulos and Pericles Pilidis. Introduction of intercooling in a high bypass jet engine. Number ASME 2000-GT-150, 2000.

[7] Pok-wang Kwan, David R H Gillespie, Andrew M Rolt, and Rory D Stieger. Aerodynamic loss mechanisms in an aero engine intercooler. In International Symposium on Air Breathing Engines 2013, number ISABE-2013-1213, 2013.

[8] Pok-wang Kwan, David R H Gillespie, Rory D Stieger, and Andrew M Rolt. HEAT TRANSFER PERFORMANCE OF AN INTERCOOLER FOR A HIGH BYPASS RATIO TURBOFAN ENGINE. In International Symposium on Air Breathing Engines 2013, number ISABE2013-1214, 2013.

[9] Xin Zhao, Tomas Grönstedt, and Konstantinos G. Kyprianidis. ASSESSMENT OF THE PERFORMANCE POTENTIAL FOR A TWOPASS CROSS FLOW INTERCOOLER FOR AERO ENGINE APPLICATIONS. Number ISABE-2013-1215, 2013.
[10] William Camilleri, Eduardo Anselmi, Vishal Sethi, and Andrew Rolt. Performance Assessment of a Geared Turbofan with Intercooling and a Reverse Flow Core. Number ISABE-2013-1713, 2013.

[11] Esmail Najafi Saatlou, Vishal Sethi, Riti Singh, and Pericles Pilidis. Techno-Economic and Environmental Assessment of Conceptual Intercooled Aero Engine Design for Long Range Application. Number ISABE-2013-1727, 2013.

[12] T. Shinmyo, S. Teramoto, K. Okamoto, and T. Nagashima. Optimization of intercooled turbofan jet thermodynamic cycle considering weight penalty and pressure loss of heat exchanger. Transactions of the Japan Society for Aeronautical and Space Sciences. accepted for publication.

[13] Janna S. William. Engineering Heat Transfer, Third Edition. CRC Press, 2009.

[14] J. Stasiek, M.W. Collins, M. Ciofalo, and P.E. Chew. Investigation of flow and heat transfer in corrugated passages - I. experimental results. International Journal of Heat and Mass Transfer, 39(1):149 164, 1996.

[15] D. A. Sagerser, S. Lieblein, and R. P. Krebs. Empirical expressions for estimating length and weight of axial-flow components of vtol powerplants. Technical Report NASA TM-X-2406, NASA, 1971.

[16] Yongsheng Lian, Akira Oyama, and Meng-Sing Liou. Progress in design optimization using evolutionary algorithms for aerodynamic problems. Progress in Aerospace Sciences, 46(5-6):199-223, July 2010.

[17] Masamichi OGAWA, Tetsuya SATO, Hiroaki KOBAYASHI, and Hideyuki TAGUCHI. Multiobjective Design Optimization of Supersonic Jet Engine in Different Cruise Mach Numbers. JOURNAL OF THE JAPAN SOCIETY FOR AERONAUTICAL AND SPACE SCIENCES, 57(670):453-460, November 2009. in Japanese.

[18] Anindya Chatterjee. An introduction to the proper orthogonal decomposition. Current science, 78(7):808-817, 2000.

[19] Philip Holmes, John L. Lumley, and Gal Berkooz. Proper orthogonal decomposition. In Turbulence, Coherent Structures, Dynamical System and Symmetry, pages 86-128. Cambridge Univ Press, 1996.

[20] Akira Oyama, Taku Nonomura, and Kozo Fujii. Data Mining of ParetoOptimal Transonic Airfoil Shapes Using Proper Orthogonal Decomposition. Journal of Aircraft, 47(5):1756-1762, September 2010. 